\title{
IMPROVED SPACE HEATING IN SMART RESIDENTIAL BUILDINGS BY APPLYING DYNAMIC HYDRAULIC BALANCING
}

\author{
TEICH, T[obias]; SZENDREI, D[anny]; FRANKE, S[usan]; LEONHARDT, S[ven] \& SCHRADER, M[arkus]
}

\begin{abstract}
Through the hydraulic balancing of heating systems, significant energy savings in residential buildings can be achieved. These savings refer to (primary) heating energy, as well as to (secondary) electric energy for the supporting building services. This paper addresses the use of KNXtechnology and networks (Smart Buildings) in multi-storey residential buildings to ensure a dynamic adaption of hydraulic system performance in order to increase the heating system's efficiency. In this paper the authors present the procedure of heating system segmentation into hydraulically independent units (meshes). Within these meshes, a dynamic hydraulic adaption towards homogenous mass flow allocation is achieved by positioning the valve ranges in each storey according to the current heating load via installed valve drivers. The control procedures are conducted by a central facility server algorithm. Heating loads are generated from the digital temperature settings in all corresponding rooms. The evaluation of current heat up demands enables maintaining hydraulic uniformity.In this paper, standards, requirements and determinats of the control algorithm are presented.

Key words: energy-efficiency, space heating, dynamic hydraulic balance, building automation
\end{abstract}

\section{INTRODUCTION}

One of today's most challenging, global problem is providing clean and sufficient energy for increasing industrial and residential demands. Industry and service companies try to meet these developments with so called "green solutions". Facility management, especially in the residential housing sector, can contribute large potentials to increase energy efficiency. A share of about $70 \%$ of the overall energy consumption is used for heating systems. Invests in high efficient heat generators are deferred especially in the residential housing sector. Next to heat generation, the probabilities of energy savings in heat distribution systems are not used adequately. In the future, the importance of hydraulic balanced systems is expected to increase, due to tightened legal restrictions (German Ministry Of Justice, 2007). The current dispute about the public energy concept forces facility management to accelerate its efforts in energetic reconstruction of buildings (German Ministry For Environmental Protection, 2010).

Conventional distribution systems, such as the double-pipe-networks, are technically mature and of high durability. Still, there are opportunities for energy savings in about $90 \%$ of all operated heating systems. This is caused by the missing hydraulic balance within those systems. The after-effects are delayed heating over the building, variable hydraulic conditions, increasing energy consumption (primary and secondary energy) and disturbing floating noises. In simulations, Felsmann and Hirschberg, 2007 found, that hydraulically imbalanced buildings cause $8 \%$ higher mass-flow-turnover than optimized buildings. This additional turnover results in $25 \%$ higher electrical energy demand for the circulation pumps. One major influence on energy consumption is caused by false hydraulic allocation.

KNX-technology enables controlling local networks in a variety of functions (power distribution, heating control, security installation and others). The KNX (Konnex) standard enables secure operation of various appliances on the platform of the European Installation Bus (EIB). Current room temperature control systems anticipate many environmental parameters and selfadjust heat generator settings as well as heating valve settings within the rooms. Caused by numerous, temperature settings through the users, the hydraulic conditions within a single pipe vary and influence the proper hydraulic supply of remaining heating devices within the same line (Yao et.al., 2005). Conventional measures of hydraulic balance (static) fail to compensate dynamic changes of difference pressure, caused by the named reason in most conditions. Via valve drivers on each heating device and the intelligent integration of the drivers in bus structures, the valve settings can be used to compensate these dynamics. As far as the hydraulic specifications (i.e. difference pressures throughout all working conditions, characteristic diagrams of heating valves, valve driver positions) of the pipes are known, the valve positioning can be controlled by a central facility server application. Thus, different load scenarios of the heating system can be considered in the controlling algorithms for each room in a specific pipe and dynamic hydraulic balance can be performed.

\section{REQUIREMENTS AND DETERMINANTS OF THE SPACE HEATING SYSTEM}

\subsection{Building Services (BS) Standards}

Smart home infrastructures or holistic control systems have not been installed in most multi-storey dwellings (Teich et.al., 2010). So far, most installations and their control systems have been conducted by companies of different crafts or branches. Integrative control procedures were hard to achieve that way. In the field of heating, integrative building control was impossible to maintain, due to the named reasons.

Heat transmission systems and their control are structured according to the dwelling units of the buildings (Liu et.al.,2010). Due to heterogeneous heat allocation (mass flow), most heating systems work inefficiently (Szendrei, 2010). This effect appears most notably in large heating systems (Felsmann \& Hirschberg, 2007). Most residential buildings are 
equipped with central heating systems (Guzek, 2010). Rising pipes supply the corresponding heating devices with mass flow of water and represent a single mesh. Within a mesh, the hydraulic conditions vary according to mesh-distance to circulation pump, storey height, installed system components and user settings. Beside physical influences of the building (hull damping, internal heat transmission etc.), user settings determine the primary energy demand significantly (Baopin et.al., 2009, Liu et.al., 2010). Hydraulic balancing of the heating ensures efficient heat distribution. Still, there are about $90 \%$ of all operated systems, where such measures have not been conducted (Guzek, 2010). Standard procedures of hydraulic balancing cover hydro-static adjustments for heating loads under extreme circumstances (full load). In this condition, the proper mass flow distribution can be obtained throughout the system by adjusting proper hydraulic resistance at the heating valves. In that case, every opened valve enables a homogeneous heat supply of all heating devices.

\subsection{KNX-integrated Building Services}

In about $95 \%$ of the heating season, significantly smaller mass flows have to be circulated by the pumps. (Zou, 2008). The mass flow is object to dynamic user settings. Accordingly, the statically adjusted resistances become out of tolerance and do not ensure homogeneous mass flows.

In the mesh-configuration however, physical determinants of the hydraulic components have to be considered. For each rising pipe/mesh, calculations of:

$$
\dot{m}_{m e s h}=\frac{\sum \dot{Q}}{c_{p} \bullet \Delta \vartheta}
$$

and

$$
\Delta p_{m e s h}=\sum(R \bullet l)+\sum\left(\zeta \bullet \frac{\rho \bullet \omega^{2}}{2}\right)
$$

are to be performed. With these information, different load scenarios can be modelled and deposited for facility server applications, as table 1 illustrates:

\begin{tabular}{|c|c|c|c|c|c|}
\hline \multicolumn{2}{|c|}{$\begin{array}{c}\text { decision variable value }(H D) \\
\text { for heating demand }\end{array}$} & \multicolumn{3}{|c|}{ valve range $R[\%]$} \\
\hline $\begin{array}{c}\text { ground } \\
\text { floor }\end{array}$ & $\begin{array}{c}1^{\text {st }} \\
\text { floor }\end{array}$ & $\begin{array}{c}2^{\text {nd }} \\
\text { floor }\end{array}$ & $R \_G F$ & $R \_l^{\text {st }}$ & $R \_2^{\text {nd }}$ \\
\hline 0 & 0 & 0 & 0 & 0 & 0 \\
\hline 0 & 0 & 1 & 0 & 0 & 100 \\
\hline 0 & 1 & 0 & 0 & 100 & 0 \\
\hline 0 & 1 & 1 & 0 & 75 & 100 \\
\hline 1 & 0 & 0 & 100 & 0 & 0 \\
\hline 1 & 0 & 1 & 75 & 0 & 100 \\
\hline 1 & 1 & 0 & 75 & 100 & 0 \\
\hline 1 & 1 & 1 & 65 & 75 & 100 \\
\hline
\end{tabular}

Tab. 1. possible heating load profiles

According to heating demand in the meshes, valve ranges can be tuned in to dynamically balance the meshes mass flow and ensuring adequate heat supply. The implementation of this control requires accurately working valve drivers. Valve positions represent specific flow rates. Sufficient drivers are to be found among KNX-based, continuously controlled drivers (Szendrei, 2011). The valve position is continuous-controlled by addressing the drivers via KNX-bus. This procedure integrates the heat utilisation and loads of whole facilities and effects hydraulic uniformity positively.

\section{RESULTS}

Two residential facilities have been equipped with an entire KNX infrastructure for heating and appliance control. The topology of the dwellings was configured with the ETS. The whole structure of all relevant building services, however, is deposited

With the value requests by the application FacilityManager, the single room temperature control could be accomplished. The proposed control-sequence achieves hydraulic uniformity over and in between the meshes. Additionally, the aggregation of heat up demands (intensity of required heat up load) indicates a potential for reducing forward-motion temperatures in near field heating. This analysis is part of further research. First evaluations of the convergency of actual and set temperature values indicate a uniform heat-up of the dwellings within the meshes. According to user interviews, a more comfortable heat-up of the rooms is achieved by now.

The electrical power consumption of circulation pumps could be reduced by $6 \%$ in comparison to similar systems. As an indicator, the called revolution per minute rate was compared against pumps in imbalanced systems.

\section{REFERENCES}

Baopin,X.; Fu, L. \& Hongfa, D. (2009). Field investigation on consumer behavior and hydraulic performance of a district heating system in Tianjin, China. Building and Environment, Vol. 44, Issue 2, 249-259, ISSN 0360-1323

Felsmann, C. and Hirschberg, R. (2007). Das Rohrnetz in Heizungsanlagen:eine Analyse des Teillastverhaltens und der Effizienz von Rohrnetzen. VDI-Verlag, ISBN 978-3183155194, Düsseldorf

Guzek, G. (2010). Zur Energieeinsparung in Heizungsanlagen durch den hydraulischen Abgleich. TUD-Verlag, ISBN 978-3941298590, Dresden

Liu, L.; Fu, L., Jiang, Y. \& Gou, S.(2010).Maintaining uniform hydraulic conditions with intelligent on-off regulation. Building and Environment, Vol. 45, Issue 12,2817-2822, ISSN 0360-1323

Szendrei, D. (2011). Feasibility of integrating heating valve drivers with KNX-standard for performing dynamic hydraulic balance in domestic buildings. Proceedings of World Academy Of Science, Engineering And Technology.International Conference on Electrical Power and Energy Systems 2011, Dubai, VAE, eISSN 2010-3778

Teich, T., Zimmermann, M. and Other. (2010). Intelligent Building Automation. In Karras, D.A., Moustafa K.A.F., Tang, D. (ed.), International Conference on Automation, Robotics and Control Systems. 53 - 57. ISRST. Orlando, Florida

Zou, Y. (2008).Unstetige Wärmeversorgung im Mehrfamilienhaus. Universitätsverlag Karlsruhe, 978-3866443648, Karlsruhe 